\title{
Developing an Innovative Model for Managing Student Engagement
}

\author{
Stephen Ellis \\ Business and Management Faculty, Regents University London
}

\begin{abstract}
This paper highlights some key issues around student engagement within but not restricted to $U K$ Business Schools. It is written from an educational practitioner basis and argues that without significant change the current position is suboptimal and may be unsustainable chiefly due to the combined impact of two relatively new contextual drivers;

- The fundamental relationship between provider and students has changed to reflect the continued advancement of marketization

- The accepted and necessary role of the business school is under reconstruction in response to the demands and needs of a variety of stakeholders

The conclusion suggests a new, broadly mapped preliminary model as a way to safeguard the business school offer for future generations of students and further the debate on how to achieve the significant changes required. Business schools are not homogenised, and the concept of student engagement is multifaceted, so the model is equally multifaceted to allow for individualisation and tailoring to the needs of the case at hand. The model is not yet tested and is offered for others to field test and critique.
\end{abstract}

\section{Introduction}

Revisiting the theme of student engagement with learning, aligned with recent changes in the background context of learning, specifically (but not exclusively in UK business schools) gives the opportunity to look afresh at the challenges faced. The first area to reflect on is the question of 'Engagement with what?' What is it that we are expecting now students to engage with and why is it not universally happening? The paper flags some of the likely impacts on the perceived reduction in engagement propensity of HE students, social media distractions being a very high profile one. It also draws parallels with the experience of many employees, (graduate or not), in the contemporary workplace where disengagement and resulting suboptimal performance is not uncommon.

The continued march of marketization, (the characterisation of students as consumers and their desire to uphold their concomitant rights), into the business school sector is also considered as a driver of potentially disengaged behaviour as the balance of power at least theoretically if not de facto shifts to the payer/user and where the role of the student as consumer is increasing.

The paper outlines where this research approach will progress over the next year and suggests clear and fruitful further areas for research into this crucial and relevant area.

\section{Student engagement with what?}

"If we as teachers cannot make our subject matter relevant to our students, perhaps it shouldn't be in the curriculum at all! To ensure relevance in our material, might we take the trouble to understand why students have enrolled in our programmes and courses, and what they expect to gain from them?" Pereira and Mullins [20].

There is much literature and significant research around on employee engagement typified by the work of Holbeche and Matthews [12], and historically rooted in the classic school of Taylorism in Mulder [18] and Peters and Waterman [22]. Others such as Peters [21], Levesque [15] clearly highlight the need to focus on employee engagement to improve the chance of achieving organisational aims and employee satisfaction, which are often considered to be closely correlated.

Modern thinking on management styles supporting full involvement of employees as opposed to a 'command and control' style hinge on the belief that high engagement drives better performance [15]. Where this has been achieved, evidence is provided by well publicised case studies that high engagement gives better creativity, better quality of customer care, improved processes, increases returns [24].

The logic of this interpretation is compelling but how, if at all, does it translate into the higher education environment, where students are not employees, nor are they generally compelled to attend?

To be clear this paper is considering the nuances of higher education student's engagement with their learning experiences with the objective of creating a framework for business school managers seeking to augment engagement, in a sustained way. So a clear assumption is made that:

\section{Higher student engagement $=$ better student experiences and outcomes}

This is not a new hypothesis and is confirmed by studies such as Rumberger and Lim [23] where 
levels of engagement are tied to high school dropout rates, and Wylie and Hodgen [28] who consider the causes of disengagement over a longer period but all the while assuming that the high engagement is a good and productive situation for students to be in. Student engagement, irrespective of the specificity of its definition, is generally associated positively with desired academic, social, and emotional learning outcomes [13].

The literature on employee engagement also tells us why achieving and sustaining higher levels, even if they do lead to greater productivity, is often not a simple task. Some employees simply may not wish, or be able, to be engaged. Some employment situations, (particularly in the new 'gig economy' sector) do not easily lend themselves to developing more engaged and sustained relationships, Maier [16] for example, constructed a hugely entertaining critique of the engagement movement through her reference to common practices and opportunity for massively disengaged workers in the French Electricity giant EDF and elsewhere.

Whether any of the principles of securing employee engagement can be transferred to students particularly in an increasingly marketised environment is debatable. The normal 'master servant' employee relationship is actually reversed as the student is paying (indirectly in most UK cases) for their tutor, yet the tutor is still in the commanding, expert position he or she is not 'employed' by the student but is both defining, delivering and probably in large part managing the evaluation of the service. One could say that academics are effectively still 'marking their own homework'

These ideas underpinned an interactive workshop on 'Engagement' at the 2017 London International Conference on Education, at Cambridge University where I found that delegates shared both my concerns and experiences.

The conscious decision to attend a business school is often a result of the desires of the individual and opportunities available to them. So, to voluntarily enter a programme with which I am not going to be engaged at high cost to myself seems to defy logic. A logical judgement has to be made that the costs of the chosen programme are outweighed by the benefits. Aside from the financial cost, (including the opportunity cost of not earning whilst attending), there is also a decision to devote both time and effort over a number of years to achieve something from the experience. Willetts [27] suggests that the cost-benefit equation of attending university for students is very much tilted in favour of the student and society both economically and in non-economic measures such as quality of life, health, mental wellbeing etc. But even this optimistic assessment assumes that students engage and can therefore secure the maximum benefit from their investment. The non-engaged student retains all the costs (real and hidden) but will not be cashing in the benefits, nor, I would argue, will society. There is room therefore for greater work to be done on the real reasons why students choose to go to university, as the propensity for low engagement suggests there must be other, more significant drivers.

The UK government has (February 2018) launched a substantial review into University funding to consider many aspects, but one key one is the current anomaly that pretty much all UK undergraduate courses are priced at the same amount regardless of the quality, perceived or otherwise, and regardless of the return to the student, however measured and the return to society. This is a clear indication that the market forces which were intended to flow into university funding regimes has not happened and that differentiated fees reflecting the above factors, and the cost of delivery may well be seen in the future.

The annual Student Academic Experience Survey run by the HE Policy Institute and the HEA in 2017, based on a survey of 1400 current UK students, engaged or otherwise, found that satisfaction with university in terms of value for money had fallen for the fifth year in a row. Only $35 \%$ of the sample felt that university was 'good' or 'very good' value. $65 \%$ of respondent felt that value for money was 'poor' or 'very poor' double since 2012. Any commercial operation faced with this type of evidence from its client base would already be panicking and probably looking for an alternative market, yet our universities do not seem to be.

Manifestations or at least indicators of high student engagement from an academic perspective might include:

- Full attendance and contributions at all teaching sessions

- Payment of all fees and expected costs on time

- Involvement with the extra- curricular activities on offer

- Membership and active participation in societies and clubs

- Completion of all preparatory work, full use of the virtual learning environment and library

- Involvement in quality improvement for future programme developments through committee work etc.

- Acting on feedback given and considering how to enhance their own learning

But how realistic, authentic or achievable is this list? There may be few students who would fit this pattern, but I believe them to be a rare and declining breed for a range of reasons. Such a description might fit well with someone who is interested and highly motivated in learning for its own sake. But 
many students are concerned with things other than their learning and may have far more interesting and engaging things to do with their time. They may also increasingly be working part-time to fund themselves, which can be a major distraction to full and engaged participation.

From a student perspective the definition of engagement would probably look very different and this is perhaps the source of the problem. Engagement is primarily being defined and consequently measured by those with a huge vested interest not by the people expected to be engaged. As an academic it is arguably very beneficial for me (and the institution) to describe my tutees as 'disengaged'. I can use this as an unquestionable reason for poor performance (theirs and mine). I can support my view by pointing to the clear and often easily measurable factors listed above, so my case is largely unchallenged. Perhaps it is time to look from the perspective of the client and see what their key engagement drivers which are is precisely where the new model proposed here is located.

Questions on student engagement have captured the interest and curiosity of international researchers from a range of disciplines, including educational psychology, developmental psychology, public health, and teacher education for the past two decades [7].

Active research on student engagement has occurred primarily in the past 25 years, advancing with an article in 1985 by Mosher and McGowan. But it could be argued that the internet and social media revolution has rendered many such studies somewhat restricted to their time. At one level the rise of alternative distractions for learners is now much greater than before and does not appear to be ebbing, if anything it is growing exponentially. The average social media user now has 8 different accounts, using digital social networks for over 2.5 hours per day, i.e. easily the equivalent of one working day per week, (GWI Social Flagship report 2017). Getting news, being entertained, keeping up with others, and filling in spare time are amongst the top reasons for this activity, learning is not.

There are many questions and unresolved issues still related to student engagement, however, there is also an emerging general consensus regarding a number of facets of student engagement theory and research, such as the belief that engaged students do more than just attend or perform academically; they also put forth discretionary effort, they persist positively, self-regulate their behaviour toward personal and imposed goals, challenge themselves to exceed, and enjoy the challenges and learning [13].

Student engagement is also undoubtedly considered to be a multidimensional construct - one that requires a thorough understanding of processes and connections within the learning environment (e.g., positive adult-student and peer relationships) and active student behaviour e.g., attendance, participation, effort, prosocial behaviour [2], [19].

The role of context cannot therefore be ignored and engagement is not conceptualized as a relatively fixed attribute of the student but rather as an outcome with a range of causations. A hugely alterable state of being that is highly influenced by the capacity of school, family, and peers to drive. This is actually very good news because it means that direct interventions can have a positive (or negative) impact, if only the right interventions are made, see Bempechat and Shernoff [4] where parental influences on engagement are explored, and Lam et al. [14] where the power of context is more fully considered.

Defining student engagement has been addressed by other writers, e.g. Skinner and Pitzer [26], but spending time on agreeing the definition of a concept that is largely understood to be problematic is likely to detract from more productive, solution-based thinking. We need to be wary of the danger of throwing more resources and effort down a 'pipeline' that is not working due at least in part to a lack of student engagement. If a lack of engagement is creating a situation where the pipeline of learning is blocked, leaky or narrowed and the subsequent learning outputs and student experiences reduced, we will only ever obtain a poor return for even more effort. It is impossible to measure the loss from the leaks, but it could be that greater effort to prevent the leaks, i.e. reduce disengagement, might give a better return than increasing effort put into the start of the process.

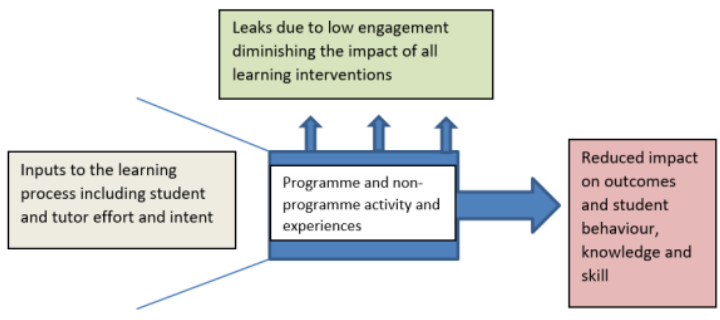

Figure 1. Disengagement creating a 'Leaky Learning' Pipeline

The desire for enhancing student engagement reinforces the notion that effective instruction explicitly considers and programs for the role of student motivation on learning outcomes [29]. This is not however a universally accepted viewpoint as the notion of tailoring a curriculum offer to the needs of the end receivers, although very much in tune with the concept of the student as a 'client' has a central flaw in that an inexperienced student cannot actually know what it is they need to focus on or how to develop their skills? Surely that is the job of the educational specialist? 
If we were to ask students what they wanted from their programme, (as I have many times), it might yield answers such as:

- Minimal assessment, no exams

- No classes before 10.00 or after 16.00 and definitely not on Friday

- Longer holiday periods

- No negative feedback

- No extra-curricular work etc.

None of these responses demonstrate much in the line of engagement so further research into what is creating and maintaining the gap of expectations between provider and consumer is vital.

The increase in student engagement measures with adequate psychometric properties has cemented the power and value of student engagement as a useful variable for data-driven decision-making efforts in schools [1], [3], [10]. So, we can now measure engagement more accurately and therefore we may justify feeling the need to manage it better.

There is an emerging intervention database that suggests evidence-based or promising strategies for educators to employ to enhance student engagement [8]. But are we pursuing a largely unattainable, or at best moving goal here?

As an indication of the degree of disengagement displayed by some students, the only question one of my undergraduate students ever asked me over two full terms in 2017/8 was;

\section{"Is it true that the first week of term attendance is not recorded?"}

i.e. Do I really need to be here this week? The question illustrates a clear lack of connection to anything that was going on in the educational aspects of their programme but they resented not getting an official 'tick' for being present. Although researchers have reached some degree of consensus that student engagement is multidimensional, agreement on the multidimensionality itself differs. It may be that consensus will only be achieved in respect that student engagement is multidimensional, and, researchers will need to define clearly their conceptualization in each study [7].

The relationship between and/or differentiation of engagement and motivation is also subject to debate [1], [2]. Are motivation and engagement separate? One can one be motivated but not actively engaged in a task or goal accomplishment. Recently, there has been a proliferation of definitions of student engagement. These conceptualizations vary further along a number of other dimensions, such as participation, observed behaviour, unforced or independent action, emotional connection, investment, and so on [2].
"Motivation influences the amount of time and effort students devote to learning and supports their continued engagement when difficulties arise" [11].

So the two concepts (motivation and engagement) are deeply intertwined. Further to this the imperative of engagement is emphasised by Pereira and Mullins (2018) for whom 'Learning Driver \# 1 (of 7) is; 'People learn best when they are actively engaged in their learning.' Learning driver \# 5 is 'People learn best when they are motivated'.

Some studies have considered engagement as a process, while others conceptualize it as an outcome [2]; [25]. But if it is not happening the debate is redundant.

Understanding whether engagement is the ultimate outcome, or a process to other desired outcomes, is a key divide in the thinking around this. A particular concern addressed in previous work is the overlap and confusion of student engagement with motivation-to-learn variables. The study of human motivation is wide and prolonged and it could be argued that there is a clear connection between the two concepts.

Engagement, or the lack of it, is thought to be especially important for apathetic and discouraged learners [5] and those at high risk for dropping out, but the primary appeal of the engagement construct is that it is relevant for all students. The universal appeal of engagement is underscored by high school reform efforts that explicitly address students' motivation to learn and engagement with school.

There is also increasingly a third-party factor here, the funder or emotional supporter, in many cases the student's parent. This party has no direct experience of the education that their charge is receiving, (perhaps a good thing), but in the marketized world we need to consider what are they expecting their sons or daughters to get from the experience?

There has been a significant change in the experience of a university education from when Enoch Powell MP described it as:

'A university is an institution which is peculiar in a precise and definable way. It is a place where there live side by side in mutual intercourse persons whose life is dedicated to the pursuit of knowledge for its own sake, regardless of the consequences or applications of the knowledge thus acquired ... it is a place to which to resort, during the formative years of early adult life.'

Speech by Enoch Powell at Magdalene College, Cambridge, 12 June 1991 [27]. 
Mass participation in HE now brings with it mass interest and mass debate about what a university experience should be, and how can we ensure it fulfils its promise for those who attend?

The preceding discussion points to some clear aspects of what a new engagement-focused model might contain. At the end of this paper the model proposed is outlined in more detail, but the first two elements of the model can be introduced here.

Students (and their sponsors) acting more from the mind-set of the client are arguably more likely to be as engaged with the surroundings the 'environment' of their campus (virtual and real) as they are with the specifics of their particular programme. Many business schools to their credit in recent years have recognised this and spent millions on refurbishment creating a welcoming and pleasant facility in which to study. The second element of the model is concerned with the way that the business school engages with its students, i.e. via ensuring that its rules and processes are 'elegant' and enabling rather than restrictive and unsympathetic with regulations that recognise the shift to client status. For example, why does the client (student) have to agree to do things (like examinations, classes etc.) when you (the business school) say and not when it is convenient to me? What if I do want to take some time off? 'I am paying and therefore it's my right to choose what I get and when.'

As evidence for this a recent story, (Guardian 7th Feb 2018), reports that students are using their newfound client status to flex their muscles by demanding compensation of any classes cancelled as a result of planned industrial action.

\section{Passive disengagement as the new norm}

Various recent surveys by CIPD, Gallop and Towers Watson consistently suggest that around $65 \%$ of employees are not fully engaged suggesting that passive disengagement is the norm over time punctuated by sporadic engagement periods for a specific issue or reward. For an employee to be passively disengaged does not mean they are deliberately poor performers or visibly demotivated, but they are not going to 'go the extra mile', or sacrifice their interests for those of their employer. How would this concept translate into the student situation?

Students who are fully engaged in their studies and see real benefits in being so, (far beyond the transactional nature of assessment grades), are likely to gain more from the learning experience for them and fellow students (and their tutors); it is more likely to be a hugely rewarding experience. However, where the student body does not show a strong level of engagement the opposite will also be true. Passively disengaged students exhibit their disengagement in a range of observable ways:

- poor attendance

- poor behaviour

- cheating (plagiarism or buying in authored work)

- $\quad$ no desire or intention to complete any work that does not leading directly to an assessed grade

- minimal involvement with the wider, enriched curriculum or the amazing opportunities often developed to enhance campus life

- refusal to attend programme committees, or student union involvement

Whilst professional educators may agree that this is clearly not a good way to proceed, we must recognise that the features listed above are not now unusual amongst many business school (and other) students.

Perhaps if the effort of achieving the very status of a university student were more demanding, or at least as demanding as it was in the past, this would itself engender a stronger desire to both maintain the status (i.e. progress on one's course) and even excel whilst there. But with the barriers to entry being reduced under pressure to maintain fee income it would appear that obtaining a place is now easier than it has ever been. In the UK the current participation rate of both sexes going to university has been steadily climbing to $48 \%$ in 2014-5, (source; UK Government statistics on-line; participation rates in HE September 2015), whilst application rates in 2014 were $47.9 \%$ (source; Cohort application rates by age 19, UCAS 2017). In other words, their does not seem to be much discrimination between application and admission.

Dropping out later in the programme is a double whammy as the student will still have all the financial and opportunity costs stacked up but not the much-desired certificate to allow them to cash in. Indeed, explaining the reasons for dropping out, even if they are wholly valid are likely to create a negative impression on any prospective employers, not to mention the disappointment of those who backed the original decision, however inappropriate it may have been, to undertake the journey.

This new, less restrictive approach to admissions may be applauded in some circles, as it appears to be an opportunity to drive social mobility, a long held 'crie-de-ceour' of the political left. But this deserves a much closer examination as it may well be a false dawn. With barriers to entry reduced, the rules of the game are not just significantly changed, they are actually inverted. The elite, at least in the UK are in many ways now those who do not go to business school but find their way to high status jobs through experience, entrepreneurship or other routes. 
Social mobility will not be improved if the door is slammed in the face of graduates because society's general belief in the value of 'graduateness' and its supposed superiority has vanished. Those graduating from a 'lower rated' university (however this is defined) with perhaps a lower classification of degree will not be granted the opportunities they might have imagined.

Many UK business schools are also under internal pressures to remain the 'cash cow' of their institution are opening their doors much wider than they have in the past. Added to this the continued influx of students from overseas and the off-campus sites in more attractive, (i.e. London), locations and we can see how the growth in business school numbers is being achieved. But if places are so easy to get then what has the individual student really invested in their decision to drive their engagement? The sense of being 'special' or part of an 'elite' is diminishing over time as the student realises that everyone they know is also in the same place. The emotional cost of dropping out, the ultimate signal of disengaging has consequently fallen.

If passive disengagement is to be the new norm, partly due to the increase in participation, then business schools will have a tougher job but also need to change their approach and pedagogy accordingly. This is a subject worthy of much further study.

\section{Engaging students in the socially connected world}

There are numerous pedagogic studies highlighting that there are a range of tutor styles and approaches that are more or less likely to result in improved engagement levels [6], [20].

Conventional wisdom offers the view that where students are involved and classes are interactive the impact of the learning and student engagement will be higher. But this in my view is both circular and actually misses the point completely. Greater interaction and involvement is precisely an outcome of engagement and cannot happen with any noticeable effect if the students are not engaged, interested or motivated to do it.

I experienced a false start in this area as a tutor myself a few years ago (2012) when I used the then quite new medium of eporfolios as a way of encouraging my undergraduate students to work on areas that they were interested in using the full power of social media [9]. In theory the use of such a vehicle for learning and assessment had in my view a good chance really of engaging students appealing to their technological competence, engendering student autonomy and bringing the subjects to life. They were required to use their eportfolios to gather and present evidence on their chosen topics and could use the whole range of social media sources. On top of this it had the novelty of being a very new way of working to most of the students that I assumed would appeal to those who might be tiring of traditional essays, exams etc.

This was not how it turned out however as many of the students simply did not wish to engage with this new method. Some of them even asked if they could do an exam or an essay instead because although it was boring it was easier and would take less time. Whilst some students did produce amazing work, they were a very small minority. My assumption that the opportunity to use technology would be a stimulating experience in itself was soon dashed as it was clear that the students largely had no interest in the technological possibilities; it was just another thing to do with no actual interest. They would happily spend passive but entertaining hours on social media, but anything that required productive engagement, thought and effort to analyse, critique or comment was soon dismissed as boring and uninteresting.

I subsequently abandoned the method as any sophisticated learning strategy is only as good as the engagement of the learner. As the once world heavyweight champion boxer Mike Tyson once famously said when asked how he dealt with the various strategies people had devised to beat him;

'Everyone has a great strategy, until they get a punch in the mouth.' Mike Tyson

To really engage a student the academic has to reveal something extra that the student cannot have done or seen or 'Googled. In today's knowledge intense world there is very little that really falls into this category until one enters the very advanced or experimental regions of knowledge and discovery. Within seconds any student can now, use their ubiquitous handheld device, to find any pearl of wisdom or chunk of typical business course content generally for free and available 24/7 in pretty much any location. More than this they can probably find the latest critique of any idea and offer that up as their 'learning'. One can almost see the logic of this approach, 'why do I need to spend time learning this if someone else has already done it?' The pleasure for some of the pursuit of knowledge is removed if it no longer needs to be pursued further than a GOOGLE search.

It is a new and increasing challenge for any academic to compete effectively with the world of everything instantly available to 'infotain' any student.

This reality however has not yet persuaded many business schools, (or academics) to change their predominant delivery model. Many are clinging to the belief that academics will be able to cut it in the 
face of all the entertainment enriched content that is freely available.

Knowledge, and the amazing opportunities for learning about business used to be created and transmitted largely inside the business school, it isn't any more. The more enlightened have been talking about permeable boundaries between academia and 'the real world' for many years now. In reality knowledge about everything is everywhere and is not discriminating, pretty much anyone who needs or wishes to can access it whether or not they are a student. A superior business school programme might now need to focus more on how to reduce the amount of knowledge its students get, or at least help them to filter out the redundant and discriminate against the outdated.

\section{The changing role of the business school in this new context}

If the task of seeking ways to engage students was not a sufficient challenge, any management model proposed must also look at the challenge from the external context. No business school exists in isolation and recent changes in the societal context of what is being provided are also playing a major part. This paper is too short to provide a wholesale review of the societal shifts being considered, so we will focus more here on the possible outcomes for business schools and the consequent challenges being faced.

Peters, Thomas and Smith, (2018) argue that the business side of business schools has been underplayed for many years. Their approach is very supply side heavy with no consideration of the recipient apart from the amount of cash they deliver to the business school. It is this type of approach that is leading to sub-optimal outputs and ignoring of the engagement issue.

The very unwelcome spectre of possible misselling is slowly raising its head here as there may well be a case that university recruiters are knowingly promising what the service cannot realistically deliver. The consequences of this are still to be tested fully in court but it will not be long in coming if the perceived offer falls short of the reality experienced.

More dangerously, there is a risk to the sector itself of becoming the scapegoat for offering a dream that was never possible to achieve. Stand by for the backlash from disgruntled parents, students themselves who are justifiably likely to want recompense for the time and money outlay incurred in pursuit of an impossible outcome.

Some employers can and do measure the potential quality of a graduate from the perceived standing of the university attended. There is an assumption here that the best universities will produce the best graduates. (As they take in the best applicants, there is no big surprise or achievement there.) But there is an implicit assumption here that the main purpose of a university is to prepare its students for employment, which is not actually always the case. Even if this is an accepted purposewhat type of employment are our graduates now to be prepared for?

Countless studies warn us that artificial intelligence is about to take over many graduate and non-graduate roles. We are in effect preparing those graduates who do wish to go into the employment market (still the majority) for roles that either do not exist or we do not currently understand which is no mean feat. If employment skills are the main goal, then the apprentice route might well be a better journey?

What of the courses which have no or minimal vocational content or very limited employment related context and are studied purely for their own sake? The student on such a programme is probably not seeing it as a stepping stone to a career, preparation for work may be incidental but also the last thing on their minds. Such a student may be attending university for a whole host of other reasons than to increase their employment prospects. I worked for a time in a university where over $70 \%$ of the students came from a family business background and future employability was a very low priority for them, comfortable in the knowledge that they had jobs lined up whenever they needed or wanted them.

So, the purpose or remit of the business school in the UK at least could be one or all of the following:

- A strong (and probably irreplaceable) generator of its local economy

- A potential method of increasing social mobility/ transforming the lives of SOME young people

- A way to increase the employability skills of its attendees, if that is what they desire

- A place where high quality, business relevant research is carried out

Again, this is a vast topic for further research and debate. Even though the UKs predominantly loans based system is not strictly speaking an upfront 'user pay' model, the fact that the cost to the individual has become more visible and every student can see the future debt racking up year on year, means the desire to get value for money however defined has grown.

Manifestations of this type of consumer activism are growing through students attempting to hold universities to account for promises made on such things as facilities, library resources, quality of the learning and teaching experience, and most crucially, the grades they achieve.

The implications of this are that improvements are going to be required on an ongoing basis as they are in any other commercially sensitive environment. 
Enhancement of facilities, resources and student satisfaction are going to be a clear and ongoing requirement, hence a section of the new model focusses on this specific area.

Universities have long attempted to include students in various representative bodies, (possibly via the student union) to comment on future planned developments, and feedback regularly on whatever issues they feel the need. This was in some way an exercise by the institution in partnering with them but was always a very unequal relationship. It is difficult to see how students could exercise much power in a forum which would invariably be chaired and managed by the university hierarchy. Low or poor engagement though threatens to scupper any such initiatives as the required client input will be restricted.

\section{Conclusion}

The following model is presented in the light of the new marketized world of higher education and the changing role of the business school. In this context it would seem entirely reasonable to consider first and continuously what the client thinks engagement means and work on these?

For any new model to be appreciated and adopted, it needs to be easily understood and preferably capable of aiding constructive thoughts and actions to a real problem. I believe that the discussion above has set out a clear case for change, and urgent change at that. The diagram below which sets out the new model is an attempt to present some connections and 'nudges' for senior business school managers to consider as they contemplate the issues raised by this paper surrounding student engagement. The intention is to consult further on the model both here in the UK and internationally to refine it in use'. The individual elements of the model at this preliminary stage have been arrived at via three main sources:

- Discussions with a range of colleagues, including the workshop presented at the LICE event in December 2107

- Experience gained from over 20 years as an education provider and latterly senior manager in a business school

- Focus group discussions (informal) with students

The model is presented here for further debate and discussion. It is not at all complete. It will form the basis of further research and investigation over the next year or so and will subsequently be presented more widely.

The four key elements of the model are:

- Enhancement - the drive to continuously improve
- Environment - the need to ensure that a holistic approach is maintained

- Elegance - the need to surround the learning experience with clear, supportive rules and regulations that recognise the power of the consumer

- Engagement - itself being the overall goal and direction of travel for the model and those who adopt it

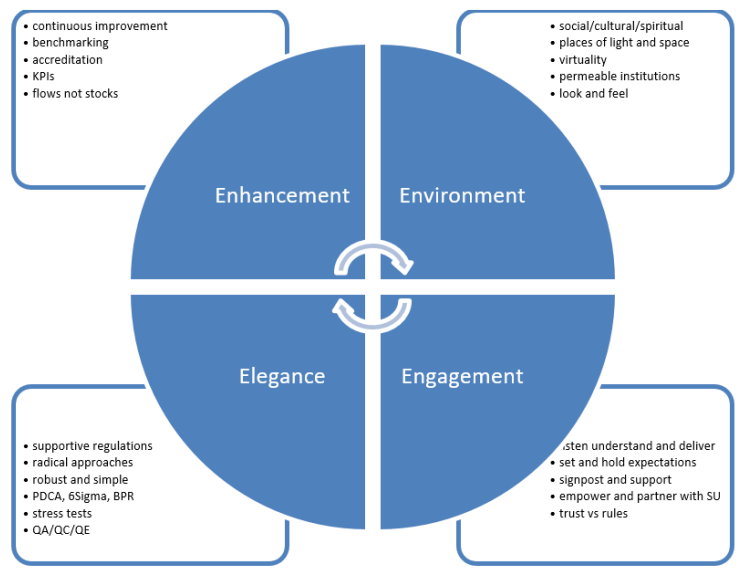

Figure 2. A preliminary model for business school managers to operate with student engagement front of mind - The 4E's of managing engagement in a business school

The content of each of the sections has, I believe, the capacity to both inform and challenge business school managers in how they think and act in support of greater student engagement.

These are now detailed below:

\section{Quadrant 1 Enhancement}

- Continuous improvement - what are the important areas defined by the 'client' (i.e. student). What do they want to be improved?

- Benchmarking - who should the school benchmark against, customer service experts i.e. not other HEIs?

- Accreditation - what are the benefits here to acquiring EPAS/AACSB etc? Or HEA status for all staff? What other accreditations would be more useful? Maybe TQM/6 sigma?

- KPIs - what measures should comprise an enhancement dashboard?

- Flows not stocks - past performance does not guarantee future enhancements; how do we make the improvement continuous? 


\section{Quadrant 2 Environment}

- Social/cultural/spiritual - how do we look after all of these aspects with true meaning within existing mission statements?

- Places of light and space - is this still a relevant vision for a business school or is it just a commercial venture?

- Virtuality - where does on-line or blended learning play a role? How does this enhance the environment? If our students want access 24/7 but not on campus how do we provide this?

- Permeable institutions - do we welcome outsiders? Or preserve exclusivity to 'manage' quality?

- Look and feel - what appeals to students/parents, old buildings, library facilities, SU areas etc.? Image is important.

\section{Quadrant 3 Elegance}

- Supportive regulations - are regulations fit for enhancing student engagement or actually barriers? Which ones make the most positive differences?

- Radical approaches - has the business school HEIs kept up with the demands of its students (and staff)? What does highly engaged performance for staff and students mean now? How is it defined in your context?

- Robust and simple - How lean are our processes? Would a new staff member be able to understand them, would a new student?

- PDCA, 6 Sigma, BPR - can any of these management techniques by applied to make the organisation function well?

- Stress tests - More elegant organisations have the capacity to ride out problems or change? Can you do this?

- $\mathrm{QA} / \mathrm{QC} / \mathrm{QE}$ - How do we define quality? How do our clients/students assure themselves of quality purely by adherence to codes?

\section{Quadrant 4 Engagement}

- Listen, understand and deliver - How do you listen to students? Mystery student shoppers?

- Set and hold manageable expectations over promising is a big temptation, under delivery is a risk.

- Signpost and support - What do today's students need more or different to the support that those of 10 years ago needed? How do we resource ourselves to do it?

- Empower and partner with SU - Where and how does the SU contribute best?

- Trust vs rules - Do senior managers trust their leaders and academics to deliver? The less they do the more rules we will need to have. Rules don't generally build much by way of engagement.

It could be that not all four quadrants are applicable everywhere and they probably cannot be the focus all at the same time. But the purpose of this paper is to stimulate thinking, discussion and hopefully take up of the model. At the start two perceived drivers for change were postulated:

- The fundamental relationship between provider, (academic institution and academics) and consumer (student) has changed with the advancement of marketization

- The role of the business school is under reconstruction in response to the demands and needs of funding providers and other stakeholders

It is hoped that the preceding commentary has unpacked some of the details behind these drivers and that the model that has been derived will address how business school managers can take their organisations forward and keep student engagement front of mind.

\section{References}

[1] Appleton, J. J., Christenson, S. L., Kim, D., \& Reschly, A., (2006). Measuring cognitive and psychological engagement: Validation of the student engagement instrument. Journal of School Psychology. 44, 427445.

[2] Appleteon, J.J., Christenson, S. L., \& Furlong, M. J., (2008). Student engagement with school: Critical conceptual and methodological issues of the construct. Psychology in the schools, 45, 369-386

[3] Betts, J., Appleton, J. J., Reschly, A., Christenson, S. L., \& Huebner, E.S., (2010). A study of the reliability and construct validity of the School Engagement Instrument across multiple grades. School Psychology Quarterly, 25, 84-93.

[4] Bempechat, J., Shernoff, D. J., Li, J., Holloway, S. D., \& Arendtsz A. L., (2012). Achievement beliefs and school engagement in low income adolescents; A mixed methods study. Paper presented at American Educational Research Association, Denver.

[5] Brophy, J., (2005). Goal theorists should move on from performance goals. Educational Psychologist, 40, 167-176 
[6] Chickering, A. \& Gamson, Z. (1987). Seven Principles for Good Practice in Undergraduate Education. AAHE Bulletin. Vol. 39, No. 7: 7.

[7] Christenson, S. L., Reschly, A. L., and Wiley, C., (2012), Handbook of Research on Student Engagement, New York; Springer.

[8] Christenson. S.L., (2008) January 22. Engaging students with school; The essential dimension of dropout prevention programs (Webinar) National Dropout Prevention Centre for Students with Disabilities.

[9] Ellis, S., and Haines, C, (2012). 'Great e-expectations, using eportfolios to assess and engage undergraduates, challenges and opportunities. ABS/HEA Conference, Innovation in difficult times, Manchester.

[10] Fredricks, J., McColskey W., Meli, J., Mordica, J., Montrosse, B., \& Mooney, K., (2011). Measuring student engagement in upper elementary through high school; A description of 21 instruments (Issues and Answers Report REL 2011- No 098. Washington DC; US Department of Education, Institute of Education Sciences, National Centre for Education Evaluation and Regional Assistance, Regional Educational Laboratory Southeast. Retrieved from http://ies.ed.gov/ncee/edlabs

[11] Hidi, S. \& Renninger, K.A. (2004). Interest, a motivational variable that combines affective and cognitive functioning. In D. Y. Dai \& R. J. Sternberg (Eds.), Motivation, emotion, and cognition: Integrative perspectives on intellectual functioning and development. Mahwah, NJ: Erlbaum.

[12] Holbeche, L., and Matthews, G., (2012), Engaged, Jossey Bass

[13] Klem, A. M. \& Connell, J. P. (2004) Relationships matter; Linking teacher support to student engagement and achievement. Journal of School Health 74. 262-282.

[14] Lam, S., Wong, B. P. H., Yang, H., \& Liu, Y., (2012). Understanding student engagement with a contextual model. In S.L. Christenson, A.L. Reschly \& C., Wylie (Eds.) Handbook of research on student engagement(pp403-419), New York: Springer

[15] Levesque, P., (1995) The WOW factory, London, Irwin

[16] Maier, C., (2004) Hello Laziness, London, Orion Books

[17] Mosher, R., \& McGowan, B. (1985). Assessing student engagement in secondary schools: alternative conceptions, strategies of assessing, and instruments. University of Wisconsin Research and Development centre (ERIC document reproductive service No. ED272812.

[18] Mulder, P., (2015). Scientific Management and Taylorism. Retrieved 23.02.18 from ToolsHero: https://www.toolshero.com/quality-management/scientificmanagement/
[19] Newmann, F., Wehlage, G. G., \& Lamborn, S.D. (1992). The significance and sources of student engagement. In F. Newman (Ed.). Student engagement and achievement in American secondary schools. (pp1139). New York: Teachers College Press.

[20] Pereira and Mullins, (2018), Seven drivers of learning, Global Focus, The EFMD Business Magazine, Iss $1 \mathrm{Vol} 12$.

[21] Peters, T., (1992). Liberation Management, London BCA.

[22] Peters, T. \& Waterman, R., (1984), In search of excellence, London, Harper Collins

[23] Rumberger, R.W., \& Lim, S. A., (2008). Why students drop out of school; a review of 25 years of research (California Dropout Research Project Report \# 15). University of California Santa Barbera

[24] Semler, R., (1993), Maverick! London; Random House.

[25] Skinner, E., Furrer, C., Marchand, G., \& Kinderman, T., (2008). Engagement and disaffection in the classroom; Part of a larger motivational dynamic? Journal of Educational Psychology, 100, 765-781

[26] Skinner, E. A., \& Pitzer, J. R., (2012). Developmental dynamics of student engagement coping and everyday resilience. In S.L. Christenson, A.L. Reschly, \& C. Wylie (Eds.), Handbook of research on student engagement (pp21-44), New York; Springer.

[27] Willetts, D., (2017). A university education, Oxford, OUP.

[28] Wylie, C., \& Hodgen, E., (2012). Trajectories and patterns of student engagement; Evidence from a longitudinal study. In S. L. Christenson, A. L. Reschly \& C Wylie (Eds) Handbook of research on student engagement (pp585-599) New York; Springer.

[29] Russell, V. J., Ainley, M., \& Frydenberg, E. (2005). Student motivation and engagement. Schooling Issues Digest. Australian Government, Department of Education, Science and Training. 